\title{
Impactos das hidrelétricas na Amazônia e a tomada de decisão
}

\section{Impacts of hydroelectric dams in the Amazon and decision making}

Philip Martin Fearnside - Doutorado em Ciências Biológicas pela University of Michigan - Ann Arbor. Pesquisador titular do Instituto Nacional de Pesquisas da Amazônia (INPA). E-mail: pmfearn@inpa.gov.br.

\section{Resumo}

As barragens brasileiras na Amazônia têm grandes impactos sociais e ambientais, que são sistematicamente subestimados nos Estudos de Impacto Ambiental (EIA) no processo de licenciamento. A equipe técnica no IBAMA, responsável pelo licenciamento, tem sido ignorado para aprovar uma série de barragens, apesar dos altos impactos, da falta de consulta aos povos indígenas e dos EIA inadequados. Há projetos de lei e propostas de emendas constitucionais que ameaçam a desconfirurar ou até eliminar o sistema de licenciamento como um todo. O uso de "suspensões de segurança" neutraliza, em grande parte, o sistema judicial em seus esforços para fazer cumprir a lei que exige a consulta aos povos indígenas ou para obrigar o cumprimento das exigências do licenciamento ambiental. A gravidade deste quadro é evidente, mas entendê-lo é o primeiro passo para que sejam mudados os sistemas de tomada de decisão e de licenciamento que levam aos impactos ilustrados pela história recente na Amazônia. O Brasil dispõe de amplas opções energéticas com menos impactos socioambientais do que as barragens que recebem prioridade hoje.

\section{Palavras-chave}

Licenciamento Ambiental. EIA. Hidrelétricas. Amazônia.

\begin{abstract}
Brazil's Amazon dams have major social and environmental impacts, which are systematically underestimated in the environmental impact assessments (EIAs) submitted for licensing. The technical staff responsible for licensing has been overridden to approve a series of dams despite high impacts, no consultation with indigenous peoples and inadequate EIAs. Pending legislation and constitutional amendments threaten either gutting or abolishing outright the entire licensing system. The use of "security suspensions" has largely neutralized the judicial system in its efforts to enforce regulations requiring consulting indigenous peoples or for fulfilling environmental-licensing requirements. The seriousness of this picture is evident, but understanding it is the first step in changing the decisionmaking and licensing systems that lead to the impacts illustrated by recent history in the Amazon. Brazil has ample energy options with less socio-environmental impacts than the dams that receive priority today.
\end{abstract}

\section{Keywords}

Environmental Licensing. Impact Assessment. Hydropower. Amazon. 


\section{INTRODUÇÃO}

O Brasil já construiu uma série de grandes barragens na sua região amazônica nas últimas décadas: Coaracy-Nunes (1975), Curuá-Una (1977), Tucuruí (1984), Balbina (1987), Manso (1987), Samuel (1988), Lajeado (1999), Peixe Angelical (2006), São Salvador (2008), Dardonelos (2011), Rondon II (2011), Estreito (2012), Santo Antônio [rio Madeira] (2011), Jirau (2013), Santo Antônio [rio Jari] (2014), Teles Pires (2014), Belo Monte (2015), São Manoel (2017) e Sinop (2019) (Figura 1). Os planos para construção futura são tremendos, embora os números apresentados por vários relatos oficiais e não oficiais variem muito.

Figura 1 - Amazônia Legal brasileira e locais mencionados no texto

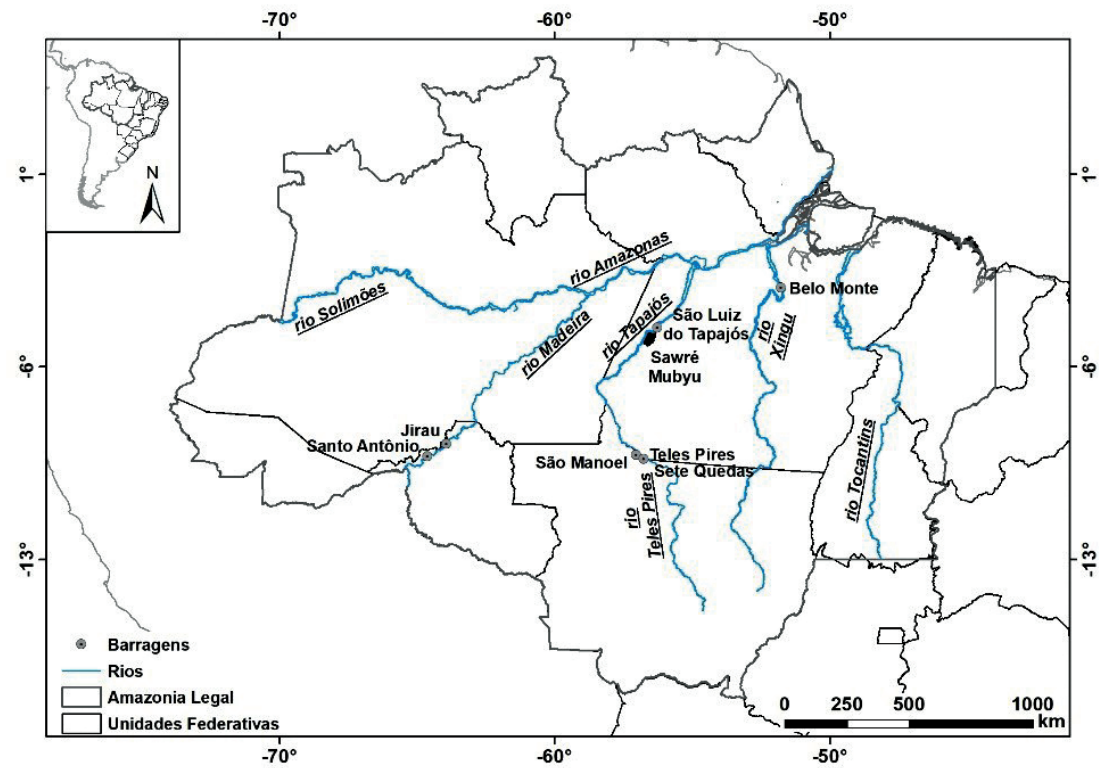

Rios: Amazonas, Madeira, Xingu, Tapajós, Teles Pires, Tocantins

Barragens: Santo Antônio, Jirau, Belo Monte, São Luiz do Tapajós, Teles Pires, São Manoel

Outros: Sawré Muybu, Sete Quedas, unidades federativas.

Fonte: $\mathrm{O}$ autor.

Em 1987, a ELETROBRAS (agência governamental responsável pelas represas) divulgou seu "Plano 2010" listando 79 barragens existentes ou planejadas na Amazônia Legal brasileira com capacidade instalada de pelo menos 100 MW, sem limitar o intervalo de anos para a construção prevista das barragens planejadas (BRASIL, 1987; ver: FEARNSIDE, 2016a). O “Plano 2010” provocou 
muitas críticas quando foi divulgado e, desde então, as autoridades brasileiras no setor elétrico não divulgaram nenhum outro plano para futuras represas que não esteja limitado a um período de poucos anos, como nos planos de 10 anos da Eletrobras (planos decenais) e em planos ocasionais de 20 ou 30 anos. Os planos para barragens estão em constante evolução, e as autoridades têm negado a existência de planos para vários das represas mais polêmicas listadas no Plano 2010. Estas barragens polêmicas podem reaparecer nos planos do setor, um exemplo sendo a barragem de Cachoeira Porteira, no rio Trombetas, que afetaria terras quilombolas, bem como uma das maiores praias de reprodução de tartarugas da Amazônia (FARIAS, 2014). Em janeiro de 2019, o anúncio do Projeto Barão do Rio Branco, pelo governo Jair Bolsonaro, indicou prioridade par essa barragem (CPISP, 2019; DIAS, 2019).

Informações muito diferentes para o número de barragens planejadas na Amazônia também resultam do tamanho mínimo das barragens consideradas em cada contabilidade. Desde 2004, o Brasil considera "grandes" as barragens com capacidade instalada de pelo menos $30 \mathrm{MW}$, mas antes desse ano o limite era de 10 MW. A mudança para 30 MW abriu uma brecha para as barragens com capacidades instaladas abaixo desse limite ("PCH": pequenas centrais hidrelétricas) a serem construídas sem licenciamento federal, que exige um Estudo de Impacto Ambiental (EIA), permitindo que essas barragens sejam construídas com uma licença estadual menos rigorosa.

O presente artigo começa com uma breve revisão dos impactos das barragens na Amazônia. Esses impactos são revisados com mais detalhes em Fearnside (2016a). Em seguida, a relação das barragens com a mudança climática é examinada, incluindo tanto o impacto das mudanças climáticas nas barragens quanto a contribuição das barragens para as emissões de gases de efeito estufa. Por fim, são apresentados os casos de barragens recentes, ilustrando as falhas dos sistemas de licenciamento e de tomada de decisões no Brasil, e algumas mudanças necessárias são sugeridas.

\section{IMPACTOS DAS BARRAGENS NA AMAZÔNIA: TERRAS INUNDADAS E POPULAÇÃO DESLOCADA}

A inundação de terras por reservatórios elimina os ecossistemas ripários e desloca as populações humanas. Áreas protegidas são frequentemente afetadas. Um exemplo é fornecido pela redução de áreas de unidades de conservação existentes para abrir caminho para as seis primeiras barragens propostas na bacia do rio Tapajós (FEARNSIDE, 2015a). Além da perda das florestas a serem 
inundadas, as represas estimulam o desmatamento nas áreas circundantes (e.g., BARRETO et al., 2011; JIANG et al., 2018).

Pouco peso tem sido dado à deslocação de populações humanas nas decisões sobre a construção de barragens. A barragem de Tucuruí (concluída em 1984 no rio Tocantins, no estado do Pará) é um exemplo, onde 23.000 pessoas foram deslocadas pelo reservatório e onde as áreas de assentamento tiveram problemas dramáticos relacionados à agricultura, saúde e falta de infraestrutura (SANTOS; BRIT'TO; MARQUES, 1996; FEARNSIDE, 1999). O número de pessoas deslocadas pela barragem de Belo Monte, no rio Xingu, no Pará, é muito maior do que aquelas que foram reconhecidas pelas autoridades elétricas (SANTOS; HERNANDEZ, 2009). Em parte, isso se deve à prática de definir a população afetada usando critérios que consistentemente minimizam o número de pessoas identificadas como "afetadas", na prática, limitando-as àquelas cujas terras são diretamente inundadas pelo reservatório (HERNANDEZ; SANTOS, 2011).

A decisão de construir uma represa no Brasil é tomada por um punhado de pessoas em instituições como os Centros Elétricos do Brasil (ELETROBRAS), o Banco Nacional de Desenvolvimento Econômico e Social (BNDES) e a Casa Civil (e.g., FEARNSIDE; LAURANCE, 2012). Embora o processo de licenciamento possa envolver anos de estudos e audiências, a decisão de construir a barragem em questão já foi tomada em um sentido real (em oposição a um sentido teórico ou legal). Aqueles que sofrerão os impactos não têm voz ou representação quando a decisão real é tomada (ver exemplos em FEARNSIDE, 1989, 1999, 2005a).

\section{IMPACTOS A JUSANTE}

Os impactos das barragens vão muito além da área diretamente inundada pelo reservatório. Os impactos a jusante são amplamente ignorados (RICHTER et al., 2010). No caso de Belo Monte, as pessoas que viviam a jusante eram consideradas não "diretamente impactadas" (BRASIL, 2009), e o governo alegou que não precisava proporcionar aos povos indígenas os mesmos direitos às consultas que se aplicariam na área a ser inundada. O chamado "trecho seco" abaixo de Belo Monte é resultado do projeto hidrelétrico, que desvia $80 \%$ da água para o lado através de uma série de canais, para retornar ao rio em um ponto de aproximadamente $100 \mathrm{~km}$ a jusante. Duas terras indígenas estão localizadas ao longo deste trecho do rio na "Volta Grande" do rio Xingu, que tem sua vazão reduzida a uma quantidade mínima, privando assim os indígenas e outros moradores dos peixes que são sua principal fonte de alimento, bem como o papel do rio para o transporte (MAGALHÃES; CUNHA, 2017). 


\section{IMPACTOS A MONTANTE}

Barragens também bloqueiam a migração de peixes, tanto ascendentes quanto descendentes do rio. Muitas espécies de peixes na Amazônia têm uma "piracema", ou seja, uma migração em massa que ascende os afluentes para se reproduzir no início da estação das enchentes (BARTHEM et al., 1991). Após a procriação nas cabeceiras, os peixes recém-nascidos descem nestes afluentes com a correnteza e depois crescem até a idade adulta no leito principal do rio Amazonas (CARVALHO; FABRÉ, 2006). Era o caso dos grandes bagres, como a dourada (Brachyplatatystoma rouxeauxii) e a piramutaba (B. vaillantii), que, antes das barragens, subiam o rio Madeira para desovar na Bolívia e no Peru. Com 920 espécies, o rio Madeira era um dos rios mais ricamente dotados de peixes no Brasil e no mundo (TORRENTE-VILARA et al., 2013). Os grandes bagres do rio Madeira tradicionalmente representavam um recurso econômico e alimentar significativo na porção brasileira do rio (DORIA et al., 2012). Também apoiaram a pesca na Bolívia e no Peru, incluindo a frota de pesca em Puerto Maldonado, no Peru (CAÑAS; PINE III, 2011). As passagens de peixe ao redor das represas não mantêm a migração de peixes que subia o rio, nem impedem a mortalidade dos peixes recém-nascidos que descem o rio (FEARNSIDE, 2014a).

\section{MERCÚRIO}

A contaminação por mercúrio é um dos custos ambientais e sociais do desenvolvimento hidrelétrico na Amazônia. O uso de mercúrio na mineração de ouro já liberou centenas de toneladas de mercúrio para o meio ambiente na região (BASTOS et al., 2006, 2015; FORSBERG; KEMENES, 2006; PFEIFFER; LACERDA, 1988). A fonte de mercúrio pode ser a mineração de ouro feita diretamente na área do reservatório, como a mineração que ocorreu na área inundada pelas barragens do rio Madeira e nas áreas planejadas para represas no rio Tapajós e seus afluentes (PFEIFFER et al., 1991). No entanto, o lançamento de mercúrio pela atividade de mineração de ouro não é necessário para ter contaminação, e reservatórios em áreas sem uma história de mineração de ouro também têm altos níveis de mercúrio, como em Balbina (FORSBERG et al., 2019; KASHIMA et al., 2001 KEHRING et al., 1998). Isto ocorre porque os solos da Amazônia, como são antigos, acumularam mercúrio ao longo de milhões de anos à medida que a poeira das erupções vulcânicas em todo o mundo se instala sobre a paisagem (ROULET; LUCOTTE, 1995). 


\section{CASCATAS DE BARRAGENS}

Outro aspecto das barragens com grandes impactos que escapa ao atual processo de licenciamento ambiental é a interconexão com outras barragens existentes ou planejadas no mesmo rio (FEARNSIDE, 1999, 2001). Essa é uma diferença importante em relação a outros tipos de geração elétrica, em que cada usina é independente de outras usinas. A produção das barragens a jusante é aumentada pela regulação dos fluxos de água em um rio, com armazenamento de água durante o período de cheia e a liberação dessa água durante o período de baixa vazão. Essa água armazenada gera eletricidade várias vezes: uma vez na barragem a montante e novamente em cada barragem a jusante. Isso cria uma tentação embutida de construir mais barragens a montante de qualquer barragem sendo avaliada para licenciamento. No caso da hidrelétrica de Tucuruí, que, em 1984, foi a primeira barragem na bacia do Tocantins/Araguaia, que cobre grande parte do sul do Pará e do norte do Mato Grosso, onde um total de 26 represas foram planejadas (JUNK; MELLO, 1990). Destas, cinco já foram construídas e seis estão planejadas na porção da bacia que fica na Amazônia Legal. Projetos planejados incluem a barragem de Marabá, que irá deslocar de 10.000 a 40.000 pessoas (e.g., RODRIGUES; RIBEIRO JUNIOR, 2010).

O caso extremo é Belo Monte, onde o reservatório da própria Belo Monte tem uma pequena capacidade de armazenamento (praticamente zero em armazenamento ativo) em relação à sua capacidade instalada de 11.233 MW. O volume de água no rio Xingu varia tanto ao longo do ciclo anual que os 11.000 MW da casa de força principal ficarão completamente inativos por três meses a cada ano, e apenas parcialmente usados para grande parte do restante (FEARNSIDE, 2017a). Esta é a raiz do perigo mais amplo representado por Belo Monte, pois Belo Monte por si só é insustentável sem água armazenada nas barragens a montante que foram publicamente propostas até 2008, quando a política declarada mudou para alegar que Belo Monte seria a única barragem no rio Xingu (e.g., FEARNSIDE, 2006; SOUSA JÚNIOR; REID, 2010). Essa afirmação foi feita por decisão do Conselho Nacional de Política Energética (CNPE), que é composto por ministros que mudam com cada administração presidencial. Esses ministros não são mais aqueles que estiveram presentes em 2008, e o CNPE é livre para mudar de ideia a qualquer momento. 


\section{BARRAGENS NA AMAZÔNIA E A MUDANÇA CLIMÁTICA}

\subsection{MUDANÇA CLIMÁTICA E A VIABILIDADE DE BARRAGENS}

Espera-se que as mudanças climáticas nas próximas décadas tornem economicamente inviáveis as muitas barragens existentes e planejadas na Amazônia, ou as tornem ainda mais inviáveis do que já estão antes dessas mudanças. A barragem de Belo Monte, por exemplo, é inviável com o clima atual (SOUSA JÚNIOR et al., 2006; FEARNSIDE, 2017a) e espera-se que seja muito pior como investimento com a diminuição da vazão do rio Xingu prevista como efeito do aquecimento global. Dependendo do modelo climático, esperase que a produção de eletricidade da represa diminua de 20 a 50\% até 2040 (MARGULIS; UNTERSELL, 2017). A estimativa maior (50\% de diminuição) corresponde ao cenário RCP8.5 do Painel Intergovernamental sobre Mudanças Climáticas (IPCC), que melhor se aproxima da tendência atual ("negócios como sempre" ou "business as usual"). Prevê-se que a vazão do rio Xingu diminua em aproximadamente 35\% até 2100 nesse cenário (SORRIBAS et al., 2016). Além desse impacto das mudanças climáticas globais, o desmatamento na bacia de Belo Monte alteraria a distribuição sazonal da vazão do rio, resultando em 33 a $38 \%$ menos geração de eletricidade até 2050, dependendo do modelo usado para projetar o desmatamento (STICKLER et al., 2013). O desmatamento aumenta a vazão no pico da enchente e diminui a vazão no período de águas baixas, um padrão que já está ocorrendo no rio Tocantins (COE; COSTA; SOARESFILHO, 2009). O aumento de vazão no período de cheias é desperdiçado do ponto de vista da geração de energia, uma vez que o fluxo de água adicional não pode ser utilizado, enquanto no período de águas baixas a vazão reduzida representa geração perdida.

As mudanças climáticas aumentam a variação interanual das chuvas na Amazônia, causando secas extremas e inundações extremas (MARENGO et al., 2011; MARENGO; ESPINOZA, 2016). As secas resultam na redução da geração de eletricidade, muitas vezes a zero, durante um período de vários meses. As enchentes podem causar danos às barragens, incluindo a sedimentação e danos por toras flutuantes, como ocorreu na enchente do rio Madeira em 2014 (GAMBET'TI, 2014). No caso do rio Madeira, a enchente de 2014 revelou dramaticamente o aumento do risco de uma grande catástrofe causada pela quebra de uma barragem durante uma inundação. Na barragem de Santo Antônio, localizada a apenas 7 $\mathrm{km}$ acima do centro de Porto Velho, três dos vertedouros não foram abertos devido a danos causados por troncos flutuantes e, se o volume de inundação 
instantâneo tivesse sido apenas 18\% maior, a capacidade dos vertedouros teria sido excedida e a barragem poderia ter quebrado (FEARNSIDE, 2015b). A represa de Jirau tinha três de seus vertedouros inacabados no momento da enchente, e $16 \%$ a mais de água poderia ter quebrado a barragem. As capacidades dos vertedouros das barragens existentes serão difíceis de aumentar, mas, para futuras represas, podem ser construídos vertedouros com maior capacidade. No entanto, o planejamento de barragens no Brasil atualmente não leva em conta as futuras mudanças climáticas.

\section{BARRAGENS AMAZÔNICAS COMO FONTES DE GASES DE EFEITO ESTUFA}

As represas amazônicas são fontes significativas de gases de efeito estufa, especialmente o gás metano $\left(\mathrm{CH}_{4}\right)$. Isso foi demonstrado por medições diretas de emissões de barragens, como Petit Saut (DELMAS et al., 2001; ABRIL et al., 2005) e Balbina (KEMENES; FORSBERG; MELACK, 2007, 2011, 2016), e por cálculos para represas como Tucuruí, Samuel, Curuá-Una e Belo Monte e Babaquara/Altamira (FEARNSIDE, 2002, 2005a, 2005b, 2009). As barragens nos trópicos úmidos emitem mais $\mathrm{CH}_{4}$ do que as de outras zonas climáticas (BARROS et al., 2011).

As represas tropicais produzem metano porque a água em um reservatório se estratifica em camadas, com uma camada quente (epilimnio) nos 2-10 m superiores de água que está em contato com o ar e contém oxigênio, e uma camada fria (hipolimnio) em maior profundidade onde o oxigênio é rapidamente exaurido e, portanto, a decomposição da matéria orgânica forçadamente termina em $\mathrm{CH}_{4}$ ao invés de $\mathrm{CO}_{2}$ (FEARNSIDE; PUEYO, 2012). Parte do metano gerado escapa para a atmosfera em forma de bolhas através da superfície do reservatório, e, se o reservatório for grande em relação ao volume de água que passa pela barragem, como em Balbina, essa emissão superficial pode ser substancial (KEMENES; FORSBERG; MELACK, 2007). Uma quantidade menor escapa por difusão, particularmente no primeiro ou segundo ano após o enchimento do reservatório (e.g., DUMESTRE et al., 1999).

O que mais dá aos reservatórios tropicais seu maior impacto no aquecimento global é a água que passa pelas turbinas e vertedouros (e.g., ABRIL et al., 2005). Esta água é extraída bem abaixo do limite (termoclina) que separa as camadas de água no reservatório e normalmente tem altas concentrações de metano. A água no fundo do reservatório está sobre pressão, e essa pressão é subitamente removida quando a água sai das turbinas (FEARNSIDE, 2004). A solubilidade 
dos gases diminui imediatamente quando a pressão é liberada, e a solubilidade diminui ainda mais à medida que a água aquece gradualmente no rio abaixo da barragem (Princípio de Le Chatalier) (JOYCE; JEWELL, 2003). Grande parte do metano forma bolhas e é liberada imediatamente. O efeito de liberar a pressão é o mesmo que ocorre quando alguém abre uma garrafa de refrigerante e o $\mathrm{CO}_{2}$ que foi dissolvido escapa em forma bolhas (ver FEARNSIDE, 2004). O impacto das barragens tropicais no aquecimento global tem sido muitas vezes subestimado, especialmente pela indústria hidrelétrica (ver FEARNSIDE, 2015c).

Há frequentes alegações de que as emissões das represas hidrelétricas da Amazônia são muito menores (e.g., SANTOS et al., 2006; OMETTO et al., 2011; FARIA et al., 2015; ver FEARNSIDE, 2011, 2016b, 2017a). No entanto, essas declarações são praticamente todas baseadas em informações bastante incompletas, omitindo as principais fontes de emissão de gases pelas barragens. Geralmente, essas alegações são baseadas apenas na emissão da superfície dos reservatórios, omitindo outras fontes, como as liberações de gases da água que passa pelas turbinas e pelos vertedouros. A decomposição de árvores mortas deixadas em pé nos reservatórios, que ocorre acima da água, também é omitida. Erros de cálculo também explicam várias alegações de emissões mínimas (ver: PUEYO; FEARNSIDE, 2011; FEARNSIDE; PUEYO, 2012).

O Quinto Relatório de Avaliação (AR5), que é o mais recente do Painel Intergovernamental sobre Mudanças Climáticas (IPCC), divulgado em setembro de 2013, aumentou consideravelmente o impacto atribuído a cada tonelada de gás metano em comparação com uma tonelada de $\mathrm{CO}_{2}$ (MYHRE et al., 2013). Durante um período de 100 anos, o relatório anterior (2007) considerou uma tonelada de $\mathrm{CH}_{4}$ a ser equivalente a 25 toneladas de $\mathrm{CO}_{2}$, e, na conversão que tem sido mais comumente utilizada, este valor foi de apenas 21, sendo este o valor usado pelo Protocolo de Quioto de 1997. No quinto relatório, incluindo retroalimentações não consideradas em relatórios anteriores, esse número sobe para 34 para o mesmo período de 100 anos (MYHRE et al., 2013). No entanto, o relatório também calcula um valor de 86 para um período de 20 anos, que quadruplica o impacto das barragens comparado com o valor de 21 e mais do que triplica o impacto comparado com o valor de 25. Muito antes do final de um horizonte temporal de 100 anos, as tendências atuais excederiam o limite estabelecido no Acordo de Paris, que exige manter a temperatura média global "bem abaixo" de uma marca $2^{\circ} \mathrm{C}$ acima da média pré-industrial. As emissões evitadas mais de 20 anos no futuro não são relevantes ao cumprimento desse compromisso.

Sendo que um projeto hidrelétrico emite gases em um pico enorme quando a barragem é construída e o reservatório enchido, seguido por emissões 
muito menores que continuam durante o restante do período de tempo em que a contabilidade é feita, a maior parte das emissões de novas represas amazônicas ocorreria precisamente na janela de tempo quando os níveis atmosféricos de gases de efeito estufa precisam ser controlados para permanecer dentro do limite do Acordo de Paris. O fato de o metano ser o principal gás emitido pelas barragens também significa que o impacto se concentra nessa janela de tempo, em contraste com a geração termoelétrica, que emite essencialmente apenas o $\mathrm{CO}_{2}$, esta emissão sendo em quantidades constantes ao longo de todo o período. Uma tonelada de metano, com um tempo médio de vida na atmosfera de apenas 12,4 anos, tem um impacto intenso no aquecimento global em um curto período de tempo, enquanto uma tonelada de $\mathrm{CO}_{2}$ tem um impacto leve a cada ano, mas que se estende por um período aproximadamente dez vezes mais longo.

\section{BARRAGENS COMO SOLUÇÃO FALSA PARA O AQUECIMENTO GLOBAL}

O fato que as barragens tropicais emitem gases de efeito estufa não é a única razão que barragens representam uma falsa solução para o aquecimento global, mesmo nos casos em que as quantidades de gases emitidas seriam menores do que as quantidades emitidas para gerar a mesma eletricidade a partir de combustíveis fósseis (e o Brasil tem muitas opções energéticas melhores que combustíveis fósseis ou barragens). O fato mais importante é que essas barragens não são "adicionais", no sentido do Protocolo de Quioto, ou seja, as barragens não são construídas devido ao subsídio do crédito de carbono. A "adicionalidade" não deve ser confundida com a classificação feita para esse quesito sob as regras atuais do Mecanismo do Desenvolvimento Limpo, que foram sucessivamente distorcidas em favor das barragens (ver FEARNSIDE, 2015d). As barragens na Amazônia estão sendo construídas por razões sem nenhuma relação à mitigação climática e ao crédito de carbono. Em vez disso, as barragens estão sendo construídas por razões que variam desde o lucro das empreiteiras de construção e das empresas de venda de eletricidade, incluindo dinheiro de subsídios governamentais, até objetivos nacionais para independência energética, e também oportunidades para corrupção, como uma série de confissões na investigação Lava Jato mostrou, demonstrando que subornos pagos para obter contratos em Belo Monte tinham um papel importante no financiamento das campanhas presidenciais em $2010 \mathrm{e}$ 2014 (ver FEARNSIDE, 2017b, 2017c).

O crédito de carbono concedido a usinas hidrelétricas permite que os países que compram o crédito emitam a quantidade de gases de efeito estufa, contada 
em equivalentes de $\mathrm{CO}_{2}$, igual à quantidade de emissão que supostamente foi evitada no Brasil por uma barragem que somente teria sido construída por causa desse crédito. As quantidades de emissão que isto permite não são pequenas: ao longo dos 7 anos de duração do projeto de crédito de carbono da barragem de Jirau, e de 10 anos no caso do projeto da barragem de Santo Antônio, o total da emissão será igual à emissão de um ano da grande São Paulo para cada barragem (FEARNSIDE, 2013a, 2015d). O pipeline ("projeto-duto") mundial de projetos de crédito carbono para hidrelétricas representa uma emissão anual igual a todo o uso anual de combustíveis fósseis no Brasil (FEARNSIDE, 2013b).

O crédito de carbono para usinas hidrelétricas traz consigo o ônus de causar impactos sociais e ambientais que excedem em muito os impactos de outras opções energéticas e de mitigação do efeito estufa. O Mecanismo de Desenvolvimento Limpo do Protocolo de Quioto exige que todos os projetos para crédito de carbono contribuam para o "desenvolvimento sustentável” (UNFCCC, 1997, Artigo 12). No entanto, o que é considerado como "desenvolvimento sustentável" é deixado para cada país decidir, e o cumprimento deste quesito apenas precisa ser afirmado por uma Agência Nacional Designada ("DNA") criada pelo próprio país. No caso do Brasil, o DNA está no Ministério da Ciência, Tecnologia, Inovação e Comunicação (MCTIC). A certificação das barragens de Jirau e Santo Antônio como "desenvolvimento sustentável” é uma demonstração da natureza inócua desta proteção teórica contra impactos socioambientais (FEARNSIDE, 2013a, 2015d).

\section{PROCESSOS DE TOMADA DE DECISÃO E LICENCIAMENTO}

Uma série de casos nos últimos anos ilustra os grandes impactos de barragens amazônicas e a necessidade de melhorar os processos de tomada de decisão e de licenciamento. Apesar de discurso ao contrário, o processo de licenciamento não faz parte da tomada de decisão sobre essas obras. A decisão real sobre a construção ou não de uma barragem é tomada por poucas pessoas no governo muito antes da elaboração dos estudos ambientais, a realização de audiências públicas e a análise pelo órgão ambiental das informações levantadas. Por serem tomadas antes de levantar informações sobre impactos, as decisões políticas ignoram muitas das consequências sociais e ambientais, e o processo de licenciamento acaba sendo um mero passo burocrático para legalizar as decisões já tomadas. O processo de licenciamento pode estar sujeito a irregularidades que resultam na aprovação de licenças apesar de grandes impactos e injustiças (FEARNSIDE, 2015b, 2020). 


\section{BARRAGENS RECENTES NA AMAZÔNIA BRASILEIRA}

As barragens de Santo Antônio e Jirau, no rio Madeira, ilustram esses problemas (FEARNSIDE, 2013c, 2014a, 2014b, 2014c, 2015b). Passou-se por cima de pareceres técnicos do IBAMA de centenas de páginas argumentando contra a aprovação das licenças (e.g., BRASIL, 2007) após trocas de chefias dentro do órgão (FEARNSIDE, 2014b). As irregularidades no licenciamento é um dos vários problemas referentes à certificação dessas barragens como "desenvolvimento sustentável" pelo Ministério de Ciência e Tecnologia para fins de obter crédito de carbono por meio do Mecanismo de Desenvolvimento Limpo (FEARNSIDE, 2013a, 2015d).

No caso de Belo Monte, o EIA tem múltiplas falhas (e.g., SANTOS; HERNANDEZ, 2009; FEARNSIDE, 2011; 2017a; VILLAS-BÔAS et al., 2015; MAGALHÃES; CUNHA, 2017; RITTTER et al., 2017). Assim como no caso das barragens no rio Madeira, passou-se por cima de pareceres técnicos do IBAMA de centenas de páginas argumentando contra a aprovação das licenças (e.g., BRASIL, 2011, 2015), neste caso com duas trocas do Presidente do IBAMA (FEARNSIDE, 2012, 2017b, 2017c).

No caso da hidrelétrica de São Luiz do Tapajós, que ainda não foi licenciada, o processo de licenciamento apresentou uma série de irregularidades (SOUSA JÚNIOR, 2014; NITTA; NAKA, 2015; ALARCON; MILLIKAN; TORRES, 2016), sendo especialmente falha a parte sobre impactos nos povos indígenas (FEARNSIDE, 2015a, 2015e). O fato que o reservatório inundaria parte de Sawré Muybu, uma área indígena cuja oficialização tem sido sucessivamente impedida devido ao interesse de partes do governo mais poderosas do que a FUNAI. O decreto inicial para criação desta terra indígena foi publicado em 19 de abril de 2016. O decreto é apenas o primeiro passo em um processo que leva, em média, oito anos para chegar à homologação, que oficializa uma Terra Indígena (LEITE, 2018). Em 04 de agosto de 2016, o IBAMA “arquivou” o processo de licenciamento (BRASIL, 2016a). No entanto, a MME continua com planos para a obra, embora com o cronograma adiada (e.g., NUNES; NEDER, 2016). Em janeiro de 2018, o secretário executivo do MME e o presidente da Empresa de Pesquisa Energética (EPE) fizeram declarações à imprensa indicando uma mudança de política para não mais priorizar grandes barragens na Amazônia devido aos seus impactos, dando prioridade para energia eólica e solar, embora não mencionassem nenhuma barragem planejada para construção até 2026 que seria sustada (FEARNSIDE, 2018a). Em maio de 2018 estes dois altos funcionários se demitiram de seus cargos quando Moreira Franco foi nomeado como o novo ministro de minas e energia, o que indica que seja ainda menor a 
probabilidade de se tornar realidade a declarada mudança de política do MME (FEARNSIDE, 2018b).

O "arquivamento" do licenciamento de São Luiz do Tapajós é uma frágil proteção, pois outros dirigentes do órgão ambiental poderiam o "desarquivar" no futuro (FEARNSIDE, 2016c). Várias propostas legislativas ameaçam a existência da área indígena Sawré Muybu, o que justificou o arquivamento do EIA. Uma é o PLS-168/2018, introduzido no Senado Federal em 10 de abril de 2018 pelo autor Senador Acir Gurgacz, que tramita na Comissão de Constituição, Justiça e Cidadania (CCJ) com relatoria do senador Romero Jucá, que tira consideração de qualquer área indígena que não seja homologada (Art. 30) (BRASIL, 2018a). Outra ameaça é a PEC-215, que tramite na Comissão Especial PEC 215/2000 da Câmara dos Deputados e que tiraria de FUNAI toda autoridade para criar terras indígenas (BRASIL, 2018b). Outra é a PEC-65, de autoria do senador Acir Gurgacz, que foi aprovada pelo CCJ em 26 de abril de 2018, que atualmente espera votação em plenária no futuro próximo, e que faz a mera entrega de um EIA uma autorização automática para construir obras como barragens (BRASIL, 2016b).

A hidrelétrica de Teles Pires causou sérios impactos ambientais e sociais, e também uma série de irregularidades no licenciamento (FEARNSIDE, 2013b, 2015f; MORETTTO et al., 2016). O que destaca mais é a destruição com dinamite, e depois com inundação, do local mais sagrado do povo Munduruku: a cachoeira das Sete Quedas, onde os espíritos dos respeitados anciões do grupo vão depois da morte (BRANFORD; TORRES, 2017a).

No caso da hidrelétrica de São Manoel, a barragem fica a apenas $700 \mathrm{~m}$ de uma terra indígena, cujo povo não foi consultado sobre a obra. Repetidos usos das "suspensões de segurança” permitiram a construção continuar até a conclusão, apesar de violações legais (ver: FEARNSIDE, 2015a). Os impactos sobre os povos indígenas tem provocado uma série de conflitos (e.g., BRANFORD; TORRES, 2017b). Um parecer do setor técnico de IBAMA recomendando contra a concessão da licença de operação (BRASIL, 2017) foi simplesmente ignorado, permitindo o enchimento do reservatório apesar de não cumprir os condicionantes, entre outras irregularidades (FEARNSIDE, 2017d).

\section{MUDANÇAS NECESSÁRIAS}

A necessidade de mudanças profundas é evidente a partir dos problemas mencionados neste breve texto, e principalmente nas referências citadas nele. A prioridade imediata é de manter as proteções legais e institucionais que existem hoje, já que essas estão ameaçadas de desmonte em curto prazo (FEARNSIDE, 2016d, 2018c). Depois há de melhorar os sistemas de tomada de decisão e de 
licenciamento para que as decisões reais sejam tomadas depois que as informações sobre impactos e benefícios de diferentes propostas de obras e políticas sejam democraticamente discutidas. A corrupção e as agendas de diferentes grupos de interesses financeiros representam fontes de vies subjacentes às decisões atuais, e medidas são necessárias para minimizar essas forças. A política energética brasileira precisa de profundas reformas para deixar de exportar eletricidade na forma de produtos eletro-intensivos, como o alumínio, e de prover os benefícios de energia à população, priorizando primeiramente a eficiência energética e depois as formas de geração com menores impactos, tais como a eólica e a solar (e.g., MOREIRA, 2012; BAITELO et al., 2013; FEARNSIDE, 2016a).

\section{AGRADECIMENTOS}

As pesquisas do autor são financiadas por: Conselho Nacional de Desenvolvimento Científico e Tecnológico (CNPq) (processos n⿳ํㅜ 305880/2007-

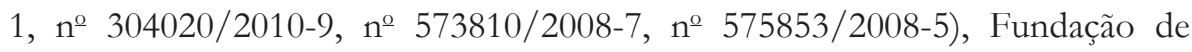
Amparo à Pesquisa do Estado do Amazonas (FAPEAM) (processo no 708565) e Instituto Nacional de Pesquisas da Amazônia (INPA) (PRJ13.03). Este trabalho é atualizado a partir de contribuições ao II Seminário Internacional América Latina - II SIALAT-2017, Belém, Pará, 27-29 de novembro de 2018 e ao Workshop Internacional: Rios, Terras e Culturas: Aprendendo com o Sistema Socioecológico do Tocantins, Palmas, Tocantins, 14-18 de maio de 2018, e tradução e atualização de Fearnside (2019).

\section{REFERÊNCIAS}

ABRIL, G.; GUÉRIN, F.; RICHARD, S.; DELMAS, R.; GALY-LACAUX, C.; GOSSE, P.; TREMBLAY, A.; VARFALVY, L.; SANTOS, M. A. dos; MATVIENKO, B. Carbon dioxide and methane emissions and the carbon budget of a 10-years old tropical reservoir (Petit-Saut, French Guiana). Global Biogeochemical Cycles, vol. 19, art. GB 4007, p. 1-16, 2005. Disponível em: https://doi.org/10.1029/2005GB002457. Acesso em: 04 dez. 2019.

ALARCON, D. F.; MILLIKAN, B.; TORRES, M. (org.). Ocekadi: hidrelétricas, conflitos socioambientais e resistência na Bacia do Tapajós. Brasília, DF: International Rivers Brasil; Santarém: UFOPA, 2016. 534p. Disponível em: https://www.internationalrivers.org/pt-br/resources/ ocekadi-hidrelétricas-conflitos-socioambientais-e-resistência-na-bacia-dotapajós-11503. Acesso em: 04 dez. 2019. 
BAITELO, R.; YAMAOKA, M.; NITTA, R; BATISTA, R. [r] evolução energética: a caminho do desenvolvimento limpo. São Paulo: Greenpeace International, 2013. 79 p. Disponível em: http://www.bibliotecadigital.abong. org.br/bitstream $/$ handle $/ 11465 / 1226 / 112$. pdf ? sequence $=1$ \&is Allowed $=y$. Acesso em: 04 dez. 2019.

BARRETO, P.; BRANDÃO JR.; A., MARTINS, H.; SILVA, D.; SOUZA JR., C.; SALES, M.; FEITOSA, T. Risco de desmatamento associado à Hidrelétrica de Belo Monte. Belém: IMAZON, 2011. 98 p. Disponível em: https://imazon. org.br/publicacoes / risco-de-desmatamento-associado-a-hidreletrica-de-belomonte-2/. Acesso em: 04 dez. 2019.

BARROS, N.; COLE, J. J.; TRANVIK, L. J.; PRAIRIE, Y. T.; BASTVIKEN, D.; HUSZAR, V. L. M.; GIORGIO, P. del; ROLAND, F. Carbon emission from hydroelectric reservoirs linked to reservoir age and latitude. Nature Geoscience, v. 4, p. 593-596, 2011. Disponível em: https://doi.org/10.1038/NGEO1211. Acesso em: 04 dez. 2019.

BARTHEM, R. B.; RIBEIRO, M. C. L. B.; PETRERE JÚNIOR, M. Life strategies of some long distance migratory catfish in relation to hydroelectric dams in the Amazon Basin. Biological Conservation, v. 5, p. 339-345, 1991. Disponível em: https://doi.org/10.1016/0006-3207(91)90037-A. Acesso em: 04 dez. 2019.

BASTOS, W. R.; GOMES, J. P. O.; OLIVEIRA, R. C.; ALMEIDA, R.; NASCIMENTO, E. L.; BERNARDI, J. V. E.; DE LACERDA, L. D.; DA SILVEIRA, E. G.; PFEIFFER, W. C. Mercury in the environment and riverside population in the Madeira River Basin, Amazon, Brazil. Science of the Total Environment, v. 368, p. 344-351. 2006. Disponível em: https://doi. org/10.1016/j.scitotenv.2005.09.048. Acesso em: 04 dez. 2019.

BASTOS, W. R.; DÓREA, J. G.; BERNARDI, J. V. E.; LAUTHARTTE, L. C.; MUSSY, M. H.; LACERDA, L. D.; MALM, O. Mercury in fish of the Madeira River (temporal and spatial assessment), Brazilian Amazon. Environmental Research, v. 140, p. 191-197, 2015. Disponível em: https://doi.org/10.1016/j. envres.2015.03.029 Acesso em: 04 dez. 2019.

BRANFORD, S.; TORRES, M. The end of a people: Amazon dam destroys sacred Munduruku 'Heaven'. Mongabay, 05 jan. 2017a. Disponível em: https:/ / news.mongabay.com/2017/01/the-end-of-a-people-amazon-dam-destroyssacred-munduruku-heaven/. Acesso em: 04 dez. 2019. 
BRANFORD, S.; TORRES, M. Brazil's indigenous Munduruku occupy dam site, halt construction. Mongabay, 19 jul. 2017b. Disponível em: https:// news. mongabay.com/2017/07/brazils-indigenous-munduruku-occupy-dam-site-haltconstruction. Acesso em: 04 dez. 2019.

BRASIL. Câmara dos Deputados. PEC 215/2000 Proposta de Emenda à Constituição. Brasília/DF: Câmara dos Deputados, 2018. Disponível em: http:/ / www.camara.gov.br/proposicoesWeb/fichadetramitacao?idProposicao $=14562$. Acesso em: 04 dez. 2019.

BRASIL. Centrais Elétricas Brasileiras S.A. Plano 2010: relatório geral. Plano Nacional de Energia Elétrica 1987/2010 (Dez. 1987). Rio de Janeiro: Eletrobrás, 1987. 269p.

BRASIL. Centrais Elétricas Brasileiras S.A. Aproveitamento Hidrelétrico Belo Monte: Estudo de Impacto Ambiental. Rio de Janeiro: Eletrobrás, 2009. 36v.

BRASIL. Ministério do Meio Ambiente. Instituto Brasileiro do Meio Ambiente e dos Recursos Naturais Renováveis. Parecer Técnico No. 014/2007 FCOHID/CGENE/DILIC/IBAMA. Brasília, DF: IBAMA, 21 de março de 2007. Disponível em: http://philip.inpa.gov.br/publ_livres/Dossie/Mad/ Documentos\%20Oficiais/Madeiraparecer.pdf. Acesso em: 04 dez. 2019.

BRASIL. Ministério do Meio Ambiente. Instituto Brasileiro do Meio Ambiente e dos Recursos Naturais Renováveis. Parecer no 52/2011. Análise da solicitação de Licença de Instalação da Usina Hidrelétrica Belo Monte, processo No 02001.001848/2006-75. Brasília, DF: IBAMA, 23 de maio de 2011. Disponível em: https://congressoemfoco.uol.com.br/upload/congresso/arquivo/parecer_ tecnico\%20ibama.pdf. Acesso em: 04 dez. 2019.

BRASIL. Ministério do Meio Ambiente. Instituto Brasileiro do Meio Ambiente e dos Recursos Naturais Renováveis. Parecer no 02001.003622/2015-08. Análise da solicitação de Licença de Operação da Usina Hidrelétrica Belo Monte, processo n 02001.001848/2006-75. Brasília, DF: IBAMA, 10 de setembro de 2015. Disponível em: https://www.socioambiental.org/sites/blog.socioambiental.org/ files/nsa/arquivos/pt_3622_2015_-_analise_da_solicitacao_de_lo_-_anexo.pdf. Acesso em: 04 dez. 2019.

BRASIL. Ministério do Meio Ambiente. Instituto Brasileiro do Meio Ambiente e dos Recursos Naturais Renováveis. Despacho 02001.018080/2016-41. Processo no 02001.003643/2009-77 - AHE São Luiz do Tapajós. Despachante: Suely Mara Vaz Guimarães de Araújo, 04 de agosto de 2016. Disponível em: http:/ /www.mpf. mp.br/pa/sala-de-imprensa/documentos/2016/arquivamento.pdf. 04 dez. 2019. 
BRASIL. Ministério do Meio Ambiente. Instituto Brasileiro do Meio Ambiente e dos Recursos Naturais Renováveis. Parecer técnico nº 93/2017-COHID/ CGTEF/DILIC. Brasília, DF: IBAMA, 25 de agosto de 2017. Disponível em: http://philip.inpa.gov.br/publ_livres/Dossie/S_Manoel/Docs_of/Parecer\%20 93_IBAMA_LO\%20São\%20Manoel_25ago2017.pdf. Acesso em: 04 dez. 2019.

BRASIL. Senado Federal. Proposta de Emenda à Constituição no 65, de 2012. Acrescenta o $\int 7^{\circ}$ ao art. 225 da Constituição, para assegurar a continuidade de obra pública após a concessão da licença ambiental. Brasília, DF: Senado Federal, 2016. Disponível em: http://www25.senado.leg.br/web/atividade/materias/-/ materia/109736. Acesso em: 04 dez. 2019.

BRASIL. Senado Federal. Projeto de Lei do Senado $\mathbf{N}^{\mathbf{o}}$, de 2018. Regulamenta o licenciamento ambiental previsto no inciso IV do $\int 1^{\circ}$ do art. 225 da Constituição Federal e dispõe sobre a avaliação ambiental estratégica. Brasília, DF: Senado Federal, 2018. https://legis.senado.leg.br/sdleg-getter/ documento?dm=7715621\&disposition=inline. Acesso em: 04 dez. 2019.

CAÑAS, C. M.; PINE III, W. E. Documentation of the temporal and spatial patterns of Pimelodidae catfish spawning and larvae dispersion in the Madre de Dios River (Peru): insights for conservation in the Andean-Amazon headwaters. River Resource Applications, v. 27, p. 602-611, 2011. Disponível em: https:/ / doi.org/10.1002/rra.1377. Acesso em: 04 dez. 2019.

CARvalho, A. R.; FABRÉ, N. N. Da foz do Amazonas aos Andes. Ciência Hoje, Rio de Janeiro, v. 39, n. 233, p. 64-67, 2006.

COE, M. T.; COSTA, M. H.; SOARES-FILHO, B. S. The influence of historical and potential future deforestation on the stream flow of the Amazon River - Land surface processes and atmospheric feedbacks. Journal of Hydrology, v. 369, p. 165-174, 2009. Disponível em: https://doi.org/10.1016/j.jhydrol.2009.02.043. Acesso em: 04 dez. 2019.

CPISP (COMISSÃO PRÓ-ÍNDIO DE SÃO PAULO). Governo anuncia nova hidrelétrica na Amazônia que impactará Terras Indígenas e Quilombolas. CPISP, 23 de janeiro de 2019. Disponível em: http://cpisp.org.br/governoanuncia-nova-hidreletrica-que-impactara-terras-indigenas-e-quilombolas/. Acesso em: 04 dez. 2019.

DELMAS, R.; GALY-LACAUX, C.; RICHARD, S. Emissions of greenhouse gases from the tropical hydroelectric reservoir of Petit Saut (French Guiana) compared with emissions from thermal alternatives. Global Biogeochemical Cycles, 15, p. 993-1003, 2001. Disponível em: https://doi.org/10.1029/2000GB001330. Acesso em: 04 dez. 2019. 
DIAS, T.D. Movido à paranoia: documentos e áudios inéditos mostram plano de Bolsonaro para povoar Amazônia contra chineses, ONGs e Igreja Católica. The Intercept, 19 set. 2019. Disponível em: https://theintercept.com/2019/09/19/ plano-bolsonaro-paranoia-amazonia/. Acesso em: 04 dez. 2019.

DORIA, C. R. C.; RUFFINO, M. L.; HIJAZI, N. C.; CRUZ, R. L. da. A pesca comercial na bacia do rio Madeira no estado de Rondônia, Amazônia brasileira. Acta Amazonica, Manaus, v. 42, n. 1, p. 9-40, 2012. Disponível em: https://doi. org/10.1590/S0044-59672012000100004. Acesso em: 04 dez. 2019.

DUMESTRE, J. F; GUEZENEC, J.; GALY-LACAUX, C.; DELMAS, R.; RICHARD, S. A.; LABROUE, L. Influence of light intensity on methanotrophic bacterial activity in Petit-Saut reservoir, French Guiana. Applied Environmental Microbiology, v. 65, p. 534-539, 1999.

FARIA, F. A. M. de; JARAMILLO, P.; SAWAKUCHI, H. O.; RICHEY, J. E.; BARROS, N. Estimating greenhouse gas emissions from future Amazonian hydroelectric reservoirs Environmental Research Letters, v. 10, n. 12, art. 124019, p.1-13, 2015. Disponível em: https://doi.org/10.1088/17489326/10/12/124019. Acesso em: 04 dez. 2019.

FARIAS, E. Hidrelétricas no rio Trombetas preocupam quilombolas e indígenas do Pará. Amazônia Real, 21 de abril de 2014. Disponível em: http:/ / amazoniareal.com.br/hidreletricas-no-rio-trombetas-preocupam-quilombolas-eindigenas-do-para/. Acesso em: 04 dez. 2019.

FEARNSIDE, P. M. Brazil's Balbina Dam: environment versus the legacy of the pharaohs in Amazonia. Environmental Management, v. 13, p. 401-423, 1989. Disponível em: https:/ /doi.org/10.1007/BF01867675. Acesso em: 04 dez. 2019.

FEARNSIDE, P. M. Social impacts of Brazil's Tucuruí Dam. Environmental Management, v. 24, p. 485-495, 1999. Disponível em: https:/ / doi.org/10.1007/ s002679900248. Acesso em: 04 dez. 2019.

FEARNSIDE, P. M. Environmental impacts of Brazil's Tucuruí Dam: Unlearned lessons for hydroelectric development in Amazonia. Environmental Management, v. 27, p. 377-396, 2001. Disponível em: https://doi.org/10.1007/ s002670010156. Acesso em: 04 dez. 2019.

FEARNSIDE, P. M. Greenhouse gas emissions from a hydroelectric reservoir (Brazil's Tucuruí Dam) and the energy policy implications. Water, Air and Soil Pollution, v. 133, p. 69-96, 2002. Disponível em: https://doi. org/10.1023/A:1012971715668. Acesso em: 04 dez. 2019. 
FEARNSIDE, P. M. Greenhouse gas emissions from hydroelectric dams: controversies provide a springboard for rethinking a supposedly "clean" energy source. Climatic Change, v. 66, p. 1-8, 2004. Disponível em: https://doi. org/10.1023/B:CLIM.0000043174.02841.23. Acesso em: 04 dez. 2019.

FEARNSIDE, P. M. Brazil's Samuel Dam: lessons for hydroelectric development policy and the environment in Amazonia. Environmental Management, v. 35, p. 1-19, 2005a. Disponível em: https://doi.org/10.1007/s00267-004-0100-3. Acesso em: 04 dez. 2019.

FEARNSIDE, P. M. Do hydroelectric dams mitigate global warming? The case of Brazil's Curuá-Una Dam. Mitigation and Adaptation Strategy for Global Change, v. 10, p. 675-691, 2005b. Disponível em: https://doi.org/10.1007/ s11027-005-7303-7. Acesso em: 04 dez. 2019.

FEARNSIDE, P. M. Dams in the Amazon: Belo Monte and Brazil's hydroelectric development of the Xingu River Basin. Environmental Management, v. 38, p. 16-27, 2006. Disponível em: https://doi.org/10.1007/s00267-005-00113-6. Acesso em: 04 dez. 2019.

FEARNSIDE, P. M. As hidrelétricas de Belo Monte e Altamira (Babaquara) como fontes de gases de efeito estufa. Novos Cadernos NAEA, Belém, v. 12, p. 5-56, 2009. Acesso em: 04 dez. 2019.

FEARNSIDE, P. M. Gases de efeito estufa no EIA-RIMA da hidrelétrica de Belo Monte. Novos Cadernos NAEA, Belém, v. 14, n. 1, p. 5-19, 2011. Disponível em: https://doi.org/10.5801/ncn.v14i1.596. Acesso em: 04 dez. 2019.

FEARNSIDE, P. M. Belo Monte dam: a spearhead for Brazil's dam building attack on Amazonia? GWF Discussion Paper 1210, Canberra, Austrália: Global Water Forum, 2012. Disponível em: http://www.globalwaterforum.org/wpcontent/uploads/2012/04/Belo-Monte-Dam-A-spearhead-for-Brazils-dambuilding-attack-on-Amazonia_-GWF-1210.pdf. Acesso em: 04 dez. 2019.

FEARNSIDE, P. M. Credit for climate mitigation by Amazonian dams: Loopholes and impacts illustrated by Brazil's Jirau Hydroelectric Project. Carbon Management, v. 4, n. 6, p. 681-696, 2013a. Disponível em: https://doi. org/10.4155/CMT.13.57. Acesso em: 04 dez. 2019.

FEARNSIDE, P. M. Carbon credit for hydroelectric dams as a source of greenhouse-gas emissions: The example of Brazil's Teles Pires Dam. Mitigation and Adaptation Strategies for Global Change, v. 18, n. 5, p. 691-699, 2013b. Disponível em: https:/ / doi.org/10.1007/s11027-012-9382-6. Acesso em: 04 dez. 2019. 
FEARNSIDE, P. M. Decision-making on Amazon dams: Politics trumps uncertainty in the Madeira River sediments controversy. Water Alternatives, v. 6, n. 2, p. 313-325, 2013c. Disponível em: http://www.water-alternatives.org/index. php/alldoc/articles/vol6/v6issue2/218-a6-2-15/file. Acesso em: 04 dez. 2019.

FEARNSIDE, P. M. Carbon credit for hydroelectric dams as a source of greenhousegas emissions: The example of Brazil's Teles Pires Dam. Mitigation and Adaptation Strategies for Global Change, v. 18, n. 5, p. 691-699, 2013d. Disponível em: https:/ / doi.org/10.1007/s11027-012-9382-6. Acesso em: 04 dez. 2019.

FEARNSIDE, P. M. Impacts of Brazil's Madeira River dams: Unlearned lessons for hydroelectric development in Amazonia. Environmental Science \& Policy, v. 38, p. 164-172, 2014a. Disponível em: https://doi.org/10.1016/j. envsci.2013.11.004. Acesso em: 04 dez. 2019.

FEARNSIDE, P. M. Brazil's Madeira River dams: a setback for environmental policy in Amazonian development. Water Alternatives, v. 7, n. 1, p. 156-169, 2014b. Disponível em: http://www.water-alternatives.org/index.php/alldoc/ articles/vol7/v7issue1/244-a7-1-15/file. Acesso em: 04 dez. 2019.

FEARNSIDE, P. M., As barragens e as inundações no rio Madeira. Ciência Hoje, Rio de Janeiro, v. 53, n. 314, p. 56-57, 2014c. Disponível em: http:// cienciahoje.org.br/artigo/barragens-e-inundacoes-no-rio-madeira/. Acesso em: 05 dez. 2019.

FEARNSIDE, P. M. Amazon dams and waterways: Brazil's Tapajós Basin plans. Ambio, v. 44, n. 5, p. 426-439, 2015a. Disponível em: https://doi.org/10.1007/ s13280-015-0642-z. Acesso em: 04 dez. 2019.

FEARNSIDE, P. M. As barragens do rio Madeira: uma espada de Dâmocles pairando sobre Porto Velho. In: FEARNSIDE, P. M. (ed.). Hidrelétricas na Amazônia: impactos ambientais e sociais na tomada de decisões sobre grandes obras. Manaus: Editora do Instituto Nacional de Pesquisas da Amazônia, 2015b. Disponível em: http://philip.inpa.gov.br/publ_livres/2015/Rio_Madeira_ Espada_de_Damocles-Série_completa.pdf. Acesso em: 04 dez. 2019.

FEARNSIDE, P. M. Emissions from tropical hydropower and the IPCC. Environmental Science \& Policy, v. 50, p. 225-239, 2015c. Disponível em: https://doi.org/10.1016/j.envsci.2015.03.002. Acesso em: 04 dez. 2019.

FEARNSIDE, P. M. Tropical hydropower in the Clean Development Mechanism: Brazil's Santo Antônio Dam as an example of the need for change. Climatic Change, v. 131, n. 4, p. 575-589, 2015d. Disponível em: https://doi. org/10.1007/s10584-015-1393-3. Acesso em: 04 dez. 2019. 
FEARNSIDE, P. M. Brazil's São Luiz do Tapajós Dam: the art of cosmetic environmental impact assessments. Water Alternatives, v. 8, n. 3, p. 373-396, 2015e. Disponível em: http://www.water-alternatives.org/index.php/alldoc/ articles/vol8/v8issue3/297-a8-3-5/. Acesso em: 04 dez. 2019.

FEARNSIDE, P. M. A Hidrelétrica de Teles Pires: o enchimento e a morte de peixes. In: FEARNSIDE, P. M. (ed.). Hidrelétricas na Amazônia impactos ambientais e sociais na tomada de decisões sobre grandes obras. Manaus: Editora do Instituto Nacional de Pesquisas da Amazônia, 2015f, v. 2, p. 109-113. Disponível em: http:// philip.inpa.gov.br/publ_livres $\backslash 2015 \backslash$ Livro-Hidro-V2 $\backslash$ Livro_Hidrelétricas_V-2cap-23-Teles_Pires-Peixes.pdf. Acesso em: 04 dez. 2019.

FEARNSIDE, P. M. Environmental and social impacts of hydroelectric dams in Brazilian Amazonia: Implications for the aluminum industry. World Development, v. 77, p. 48-65, 2016a. Disponível em: https://doi.org/10.1016/j. worlddev.2015.08.015. Acesso em: 04 dez. 2019.

FEARNSIDE, P. M. Greenhouse gas emissions from Brazil's Amazonian hydroelectric dams. Environmental Research Letters, v. 11, n. 1, art. 011002 , 2016b. Disponível em: https://doi.org/10.1088/1748-9326/11/1/011002. Acesso em: 04 dez. 2019.

FEARNSIDE, P. M. A Hidrelétrica de São Luiz do Tapajós: 22 - Pós-escrito. Amazônia Real, 12 dez. 2016, 2016c. Disponível em: http:/ / amazoniareal.com. br/hidreletrica-de-sao-luiz-do-tapajos-22-pos-escrito/. Acesso em: 04 dez. 2019.

FEARNSIDE, P. M. Brazilian politics threaten environmental policies. Science, Washington, v. 353, p. 746-748, 2016d. Disponível em: https://doi.org/10.1126/ science.aag0254. Acesso em: 04 dez. 2019.

FEARNSIDE, P. M. Planned disinformation: the example of the Belo Monte Dam as a source of greenhouse gases. In: ISSBERNER, L-J.; LENA, P. (ed.). Brazil in the Anthropocene: conflicts between predatory development and environmental policies. New York: Routledge, Taylor \& Francis Group, 2017a. p. 125-142. Também disponível em português em: Desinformação planejada: o exemplo da Barragem de Belo Monte como fonte de gases de efeito estufa. Disponível em: http://philip.inpa.gov.br/publ_livres/2017/Desinformacao_ no_EIA_de_Belo_Monte-Serie_completa.pdf. Acesso em: 04 dez. 2019.

FEARNSIDE, P. M. Belo Monte: actors and arguments in the struggle over Brazil's most controversial Amazonian dam. Die Erde, Berlin, v. 148, n. 1, p. 14 26, 2017b. Disponível em: https://doi.org/10.12854/erde-148-27. Acesso em: 04 dez. 2019. 
FEARNSIDE, P. M. Brazil's Belo Monte Dam: lessons of an Amazonian resource struggle. Die Erde, Berlin, v. 148, n. 2-3, p. 167-184, 2017c. Disponível em: https://doi.org/10.12854/erde-148-46. Acesso em: 04 dez. 2019.

FEARNSIDE, P. M. Amazon dam defeats Brazil's environment agency. Mongabay, 20 set. 2017, 2017d. Disponível em: https:// news.mongabay.com/2017/09/amazondam-defeats-brazils-environment-agency-commentary/. Acesso em: 04 dez. 2019.

FEARNSIDE, P. M. Possível mudança na política sobre barragens amazônicas. Amazônia Real, 09 jan. 2018, 2018a. Disponível em: http:// amazoniareal.com.br/possivel-mudanca-na-politica-sobre-barragensamazonicas/. Acesso em: 04 dez. 2019.

FEARNSIDE, P. M. Represando a Amazônia sem restrições por mudanças no setor elétrico brasileiro. Amazônia Real, 16 maio 2018, 2018b. Disponível em: http://amazoniareal.com.br/represando-a-amazonia-sem-restricoes-pormudancas-no-setor-eletrico-brasileiro/. Acesso em: 04 dez. 2019

FEARNSIDE, P. M. Challenges for sustainable development in Brazilian Amazonia. Sustainable Development, v. 26, n. 2, p. 141-149, 2018c. Disponível em: https://doi.org/10.1002/sd.1725/. Acesso em: 04 dez. 2019.

FEARNSIDE, P. M. Represas hidroeléctricas en la Amazonía brasileña: impactos ambientales y sociales. Revista de Estudios Brasileños, Salamanca, v. 6, n. 11, p. 123-138, 2019. Disponível em: https://doi.org/10.14201/reb2019611123138. Acesso em: 04 dez. 2019.

FEARNSIDE, P. M. Environmental justice and Brazil's Amazonian dams. In: ROBINS, N. A.; FRASER, B. (ed.). Landscapes of Inequity: the quest for environmental justice in the Andes/Amazon region. Lincoln: University of Nebraska Press, 2020. (no prelo). Disponível em Português em: http://philip. inpa.gov.br/publ_livres/2015/Rio_Madeira_Espada_de_Damocles-Série_ completa.pdf. Acesso em: 04 dez. 2019.

FEARNSIDE, P. M.; LAURANCE, W. F. Infraestrutura na Amazônia: As lições dos planos plurianuais. Caderno CRH, Salvador, v. 25, n. 64, p. 87-98, 2012. Disponível em: https://doi.org/10.1590/S0103-49792012000100007. Acesso em: 04 dez. 2019.

FEARNSIDE, P. M.; PUEYO, S. Underestimating greenhouse-gas emissions from tropical dams. Nature Climate Change, v. 2, p. 382-384, 2012. Disponível em: https://doi.org/10.1038/nclimate1540. Acesso em: 04 dez. 2019. 
FORSBERG, B. R., \& KEMENES, A. Parecer técnico sobre estudos hidrobiogeoquímicos, com atenção específica à dinâmica do mercúrio ( $\mathrm{Hg}$ ). In: RONDÔNIA. Relatório de Análise do Conteúdo dos Estudos de Impacto Ambiental (ELA) e do Relatório de Impacto Ambiental (RIMA) dos Aproveitamentos Hidrelétricos de Santo Antônio e Jirau no Rio Madeira, Estado de Rondônia. Porto Velho: Ministério Público do Estado de Rondônia, Cobrape, 2006. p. 4-32. (Parte B, vol. I, parecer 2). Disponível em: http://philip.inpa.gov.br/publ_livres/Dossie/Mad/ Documentos\%20Oficiais/Madeira_COBRAPE/11118-COBRAP-report.pdf. Acesso em: 04 dez. 2019.

FORSBERG, B. R.; MELACK, J. M.; DUNNE, T.; BARTHEM, R. B.; GOULDING, M.; PAIVA, R. C. D.; ORRIBAS, M. V., SILVA, Jr., U. L. The potential impact of new Andean dams on Amazon fluvial ecosystems. PLoS ONE, v. 1, n. 8, art. e0182254. 2017. Disponível em: https://doi.org/10.1371/ journal.pone.0182254. Acesso em: 04 dez. 2019.

GAMBETTI, D. L. G. A cheia do Rio Madeira: causas e consequências na UHE Santo Antonio e Região. Presentation at the $6^{\text {th }}$ International Conference on Flood Management (ICFM6), 16-18 September 2014, São Paulo. Associação Brasileira de Recursos Hídricos (ABRH), Porto Alegre, Rio Grande do Sul, 46 p. 2014, 2014. Disponível em: http://philip.inpa.gov.br/publ_livres/Dossie/ $\mathrm{Mad} /$ Outros\%20documentos/Technical\%20papers/Cheia_do_rio_Madeira16_09_11h00_delfino_luiz.pdf. Acesso em: 05 dez. 2019.

HERNANDEZ, F. M.; SANTOS, S. B. M. Ciência, cientistas e democracia desfigurada: o caso de Belo Monte. Novos Cadernos NAEA, Belém, v. 14, n. 1, p. 79-96, 2011. Disponível em: http://repositorio.ufpa.br/jspui/ handle/2011/3270. Acesso em: 04 dez. 2019.

JIANG, X.; LU, D.; MORAN, E.; CALVI, M. F.; DUTRA, L. V.; LI, G. Examining impacts of the Belo Monte hydroelectric dam construction on landcover changes using multitemporal Landsat imagery. Applied Geography, v. 97, p. 35-47, 2018. Disponível em: https://doi.org/10.1016/j.apgeog.2018.05.019. Acesso em: 04 dez. 2019.

JOYCE, J.; JEWELL, P. W. Physical controls on methane ebullition from reservoirs and lakes. Environmental Engineering and Geoscience, v. 9, p. 167-178, 2003.

JUNK, W. J.; MELLO, J. A. S. N. de. Impactos ecológicos das represas hidrelétricas na bacia amazônica brasileira. Estudos Avançados, São Paulo, v. 4, n. 8, p. 126143, 1990. Disponível em: https://doi.org/10.1590/S0103-40141990000100010. Acesso em: 04 dez. 2019. 
KASHIMA, Y.; AKAGI, H.; KINJO, Y.; MALM, O.; GUIMARÃES, J. R. D.; BRANCHES, F.; DOI, R. Selenium and mercury concentrations in fish from the lower Tapajos River and the Balbina Reservoir, Brazilian Amazon. In: INTERNATIONAL CONFERENCE ON MERCURY AS A GLOBAL POLLUTANT (ICMGP), 6., Minamata-Japan, 2001. Annals [...]. Minamata, Japan: ICMGP, 2001. p. 280.

KEHRING, H. A.; MALM, O.; AKAGI, H.; GUIMARÃES, J. R. D.; TORRES, J. P. M. Methylmercury in fish and hair samples from the Balbina Reservoir, Brazilian Amazon. Environmental Research, v. 77, p. 84-90, 1998. Disponível em: https://doi.org/10.1006/enrs.1998.3836. Acesso em: 04 dez. 2019.

KEMENES, A.; FORSBERG, B. R.; MELACK, J. M. Methane release below a tropical hydroelectric dam. Geophysical Research Letters, v. 34, art. L12809, 2007. Disponível em: https://doi.org/10.1029/2007GL029479. 55. Acesso em: 04 dez. 2019.

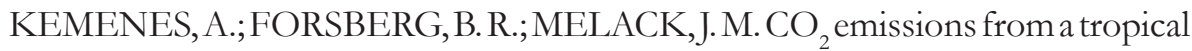
hydroelectric reservoir (Balbina, Brazil). Journal of Geophysical Research, v. 116, art. G03004, 2011. Disponível em: https://doi.org/10.1029/2010JG001465. Acesso em: 04 dez. 2019.

KEMENES, A.; FORSBERG, B. R.; MELACK, J. M. Downstream emissions of $\mathrm{CH}_{4}$ and $\mathrm{CO}_{2}$ from hydroelectric reservoirs (Tucuruí, Samuel and Curuá-Una) in the Amazon basin. Inland Waters, v. 6, n. 3, p. 295-302, 2016. Disponível em: https://doi.org/10.1080/IW-6.3.980. Acesso em: 05 dez. 2019.

LEITE, M. Levantamento da Funai aponta 27 povos isolados ameaçados por obras. Folha de São Paulo, 28 abr. 2018, p. B7. 2018. Disponível em: https:// www1.folha.uol.com.br/ambiente/2018/04/levantamento-da-funai-aponta-27povos-isolados-ameacados-por-obras.shtml. Acesso em: 04 dez. 2019.

MAGALHÃES, S. B.; CUNHA, M. C. da (ed.). A expulsão de ribeirinhos em Belo Monte: relatório da SBPC. São Paulo: SBPC, 2017. 448p. Disponível em: http://portal.sbpcnet.org.br/livro/belomonte.pdf. Acesso em: 04 dez. 2019.

MARENGO, J.A.; ESPINOZA, J. C. Review: Extreme seasonal droughts and floods in Amazonia: causes, trends and impacts. International Journal of Climatology, v. 36, p. 1033-1050, 2016. Disponível em: https:// doi.org/10.1002/ joc.4420. Acesso em: 04 dez. 2019.

MARENGO, J. A.; TOMASELLA, J.; SOARES, W.; ALVES, L.; NOBRE, C. A. Extreme climatic events in the Amazon Basin: climatological and hydrological context of previous floods. Theoretical and Applied Climatology, v. 85, p. 1-13, 2011. Disponível em: https://doi.org/10.1007/s00704-011-0465-1. Acesso em: 04 dez. 2019. 
MARGULIS, S.; UNTERSELL, N. Shaping up Brazil's long-term development considering climate change impacts. In: ISSBERNER, L-R.; LENA, P. (ed.). Brazil in the Anthropocene: conflicts between predatory development and environmental policies. New York: Routledge, 2017. p. 220-241.

MOREIRA, P. F. (ed.). Setor elétrico brasileiro e a sustentabilidade no século 21: oportunidades e desafios. 2. ed. Brasília, DF: Rios Internacionais, 2012. Disponível em: http://www.internationalrivers.org/node/7525. Acesso em: 04 dez. 2019.

MORETT'TO, E. M.; JORDÃO, C. O.; FERNANDES, E.; ANDRADE, J. Condicionantes e a viabilidade ambiental no processo de licenciamento ambiental de usinas hidrelétricas: uma análise do caso Teles Pires. In: ALARCON, D. F.; MILLIKAN, B.; TORRES, M. (ed.). Ocekadi: hidrelétricas, conflitos socioambientais e resistência na Bacia do Tapajós. Brasília, DF: International Rivers Brasil; Santarém, PA: UFOPA, 2016. p. $167-$ 182. Disponível em: https://www.internationalrivers.org/files/attached-files/ tapajos_digital_0.pdf. Acesso em: 04 dez. 2019.

MYHRE, G. et al. Anthropogenic and natural radiative forcing. In: STOCKER, T. F.; QIN, D.; PLATTNER, G.-K.; TIGNOR, M.; ALLEN, S.K.; BOSCHUNG, J.; NAUELS, A.; XIA, Y.; BEX, V.; MIDGLEY, P. M. (ed.). Climate Change 2013: the physical science basis. Cambridge: Cambridge University Press, 2013. p. 661-740. Disponível em: http://www. ipcc.ch/report/ar5/wg1/. Acesso em: 04 dez. 2019.

NITTA, R.; NAKA, L. N. (ed.). Barragens do rio Tapajós: uma avaliação crítica do Estudo e Relatório de Impacto Ambiental (EIA/RIMA) do aproveitamento hidrelétrico São Luiz do Tapajós. São Paulo: Greenpeace Brasil, 2015. 99p. Disponível em: http://greenpeace.org.br/tapajos/docs/analise-eia-rima.pdf. Acesso em: 04 dez. 2019.

NUNES, F; NEDER, V. Eletrobrás quer retomar projeto de megahidrelétrica no Tapajós. O Estado de São Paulo, São Paulo, 01 dez. 2016. Disponível em: http://economia.estadao.com.br/noticias/geral,eletrobras-quer-retomarprojeto-de-megahidreletrica-no-tapajos,10000092046. Acesso em: 04 dez. 2019.

OMETTO, J. P.; PACHECO, F. S.; CIMBLERIS, A. C. P.; STECH, J. L.; LORENZZETTI, J. A.;. ASSIREU, A. SANTOS, M. A.; MATVIENKO, B.; ROSA, L. P.; GALLI, C. S.; ABE, D. S.; TUNDISI, J. G.; BARROS, N. O.; MENDONÇA, R. F.; ROLAND, F. Carbon dynamic and emissions in Brazilian hydropower reservoirs. In: Alcantara, E. H. de (ed.). Energy resources: 
development, distribution, and exploitation. New York: Nova Science Publishers, Hauppauge, 2011. p. 155-188. Disponível em: https://www.researchgate. net/publication/272477210_Carbon_dynamic_and_emissions_in_Brazilian_ hydropower_reservoirs. Acesso em: 04 dez. 2019.

PFEIFFER, W. C.; LACERDA, L. D. de. Mercury inputs into the Amazon region, Brazil. Environmental Technology Letters, v. 9, p. 325-330, 1988. Disponível em: https://doi.org/10.1080/09593338809384573. Acesso em: 04 dez. 2019.

PFEIFFER, W. C.; MALM, O.; SOUZA, C. M. M.; LACERDA, L. D. de; SILVEIRA, E. G.; BASTOS, W. R. Mercury in the Madeira River ecosystem, Rondônia, Brazil. Forest Ecology and Management, v. 38, p. 239-245, 1991. Disponível em: https:/ / doi.org/10.1016/0378-1127(91)90145-L. Acesso em: 04 dez. 2019.

PUEYO, S.; FEARNSIDE, P. M. Emissões de gases de efeito estufa dos reservatórios de hidrelétricas: Implicações de uma lei de potência. Oecologia Australis, v. 15, n. 2, p. 114-127, 2011. Disponível em: https://doi.org/10.4257/ oeco.2011.1502.02. Acesso em: 04 dez. 2019.

RICHTER, B. D.; POSTEL, S.; REVENGA, C.; SCUDDER, T.; LEHNER, B.; CHURCHILL, A.; CHOW, M. Lost in development's shadow: The downstream human consequences of dams. Water Alternatives, v. 3, n. 2, p. 4-42, 2010. Disponível em: http://www.water-alternatives.org/index.php/volume3/ v3issue2/80-a3-2-3/file. Acesso em: 04 dez. 2019.

RITTER, C. D.; MCCRATE, G.; NILSSON, R. H.;FEARNSIDE, P. M.; PALME, U.; ANTONELLI, A. Environmental impact assessments in Brazilian Amazonia: challenges and prospects to assess biodiversity. Biological Conservation, v. 206, p. 161-168, 2017. Disponível em: https://doi.org/10.1016/j.biocon.2016.12.031. Acesso em: 04 dez. 2019.

RODRIGUES, F. S.; RIBEIRO JUNIOR, R. Construção do AHE Marabá: uma abordagem sobre opções de desenvolvimento e o seu planejamento. In: ENCONTRO LATINOAMERICANO DE CIÊNCIAS SOCIAIS E BARRAGENS, 3., 2010, Belém. Anais [...]. Belém: UFPA, 2010. Disponível em: https://www.yumpu.com/pt/document/read/35572414/acesse-o-artigocompleto-aqui-iii-encontro-ciancias-sociais-e-. Acesso em: 05 dez. 2019.

ROULET, M.; LUCOTTE, M. Geochemistry of mercury in pristine and flooded ferralitic soils of a tropical rain forest in French Guiana, South America. Water, air and soil pollution, v. 80, p. 1079-1088, 1995. Disponível em: https://doi. org/10.1007/BF01189768. Acesso em: 04 dez. 2019. 
SANTOS, S. M. S. M.; HERNANDEZ, F. M. (ed.). Painel de especialistas: análise crítica do Estudo de Impacto Ambiental do aproveitamento hidrelétrico de Belo Monte. Belém: Painel de Especialistas sobre a Hidrelétrica de Belo Monte, 2009. 230p. Disponível em: http://www.xinguvivo.org.br/ wp-content/uploads/2010/10/Belo_Monte_Painel_especialistas_EIA.pdf. Acesso em: 04 dez. 2019.

SANTOS, S. B. M.; BRIT'TO, R. C.; CASTRO, E. R. (ed.). Energia na Amazônia. Belém: Museu Paraense Emílio Goeldi, Universidade Federal do Pará, Associação de Universidades Amazônicas, 1996. 966p.

SANTOS, M. A. dos; ROSA, L. P.; SIKAR, B.; SIKAR, E.; SANTOS, E. D. dos. Gross greenhouse gas emissions from hydro-power reservoir compared to thermo-power plants. Energy Policy, v. 34, p. 481-488, 2006. Disponível em: https://doi.org/10.1016/j.enpol.2004.06.015. Acesso em: 04 dez. 2019.

SORRIBAS, M. V.; PAIVA, R. C. D.; MELACK, J. M.; BRAVO, J. M.; JONES, C.; CARVALHO, L.; BEIGHLEY, E.; FORSBERG, B.; COSTA, M. H. Projections of climate change effects on discharge and inundation in the Amazon basin. Climatic Change, v. 136, n. 3, p. 555-570, 2016. Disponível em: https://doi. org/10.1007/s10584-016-1640-2. Acesso em: 04 dez. 2019.

SOUSA JÚNIOR, W. C. de (ed.). Tapajós: hidrelétricas, infraestrutura e caos. São José dos Campos, SP: ITA, 2014. 192 p. Disponível em: http://www.riosvivos. org.br/arquivos/site_noticias_2134831519.pdf. Acesso em: 04 dez. 2019.

SOUSA JÚNIOR, W. C. de; REID, J. Uncertainties in Amazon hydropower development: risk scenarios and environmental issues around the Belo Monte dam. Water Alternatives, v. 3, p. 249-268, 2010. Disponível em: http://www.wateralternatives.org/index.php/tp1-2/1879-vol3/139-issue3-2. Acesso em: 04 dez. 2019.

SOUSA JÚNIOR, W. C. de; REID, J.; LEITÃO, N. C. S. Custos e benefícios do complexo hidrelétrico Belo Monte: uma abordagem econômico-ambiental. Conservation Strategy Fund (CSF), Série Técnica n. 4. Lagoa Santa: CSF, 2006. 90p. Disponíuvel em: https://www.conservation-strategy.org/pt/publication/ custos-e-benefícios-do-complexo-hidrelétrico-belo-monte-uma-abordagemeconômico-ambienta\#.WveQkkxFxrQ. Acesso em: 04 dez. 2019.

STICKLER, C. M.; COE, M. T.; COSTA, M. H.; NEPSTAD, D. C.; MCGRATH, D. G.; DIAS, L. C.; RODRIGUES, H. O.; SOARES-FILHO, B. S. Dependence of hydropower energy generation on forests in the Amazon Basin at local and regional scales. Proceedings of the National Academy of Science USA, v. 110, p. 9601-9606, 2013. Disponível em: https://doi.org/10.1073/pnas.1215331110. Acesso em: 04 dez. 2019. 
TORRENTE-VILARA, G.; QUEIROZ, L. J. de; OHARA, W. M. Um breve histórico sobre o conhecimento da fauna de peixes do Rio Madeira. In: QUEIROZ, L. J. de; OHARA, W.; ZUANON, J.; PIRES, T. H. S.; TORRENTE-VILARA, G.; DORIA, C. R. C. (ed.) Peixes do Rio Madeira. São Paulo: Dialeto, 2013. p. $19-25$.

UNFCCC (United Nations Framework Convention on Climate Change). Kyoto protocol to the United Nations Framework Convention on Climate Change. UNFCCC, Bonn, Alemanha, 1997. Disponível em: https://unfccc.int/ resource/docs/convkp/kpeng.pdf. Acesso em: 04 dez. 2019.

VILLAS-BÔAS, A.; GARZÓN, B. R.; REIS, C.; AMORIM, L.; LEITE, L. Dossiê Belo Monte: não há condições para a licença de operação. Brasília, DF: Instituto Socioambiental (ISA). 2015. Disponível em: http://t.co/zjnVPhPecW. Acesso em: 04 dez. 2019. 